\title{
Outcomes of Radiofrequency Ablation versus Endoscopic Surveillance for Barrett's Esophagus with Low-Grade Dysplasia: A Systematic Review and Meta-Analysis
}

\author{
Jagpal Singh Klaira Yousaf Zafar ${ }^{b}$ Navroop Nagra ${ }^{a} \quad$ Arvind R. Murali $^{c}$ \\ Mahendran Jayaraj $^{d}$ Dhruv Singh ${ }^{\mathrm{e}}$ Tarun Rustagi $^{f} \quad$ Rajesh Krishnamoorthi $^{\mathrm{a}}$ \\ aDigestive Disease Institute, Virginia Mason Medical Center, Seattle, WA, USA; ${ }^{b}$ Department of Internal Medicine, \\ Naples Community Healthcare, University of Central Florida, Orlando, FL, USA; 'Division of Gastroenterology \\ and Hepatology, University of lowa Hospitals and Clinics, lowa City, IA, USA; ${ }^{d}$ Division of Gastroenterology and \\ Hepatology, University of Nevada Las Vegas, Las Vegas, NV, USA; 'Division of Gastroenterology and Hepatology, \\ Mayo Clinic, Rochester, MN, USA; 'Division of Gastroenterology and Hepatology, University of New Mexico, \\ Albuquerque, NM, USA
}

\section{Keywords}

Barrett's esophagus · Dysplasia · Endoscopic surveillance · Esophageal adenocarcinoma

\begin{abstract}
Background: Endoscopic therapy using radiofrequency ablation (RFA) is a recommended treatment for Barrett's esophagus with high-grade dysplasia (BE-HGD) without a visible lesion which is managed by resection. However, currently, there is no consensus on the management of $B E$ with lowgrade dysplasia (BE-LGD) - RFA versus endoscopic surveillance. Hence, we performed a systematic review and metaanalysis of these comparative studies to compare the risk of progression to HGD or esophageal adenocarcinoma (EAC) among patients with BE-LGD treated with RFA versus endoscopic surveillance. Methods: The primary outcome was to compare the risk of progression to HGD or EAC among patients with BE-LGD treated with RFA versus endoscopic surveillance. Results: Four comparative studies reporting a total of 543 patients with BE-LGD were included in the meta-anal-
\end{abstract}

karger@karger.com

(c) 2021 S. Karger AG, Basel

www.karger.com/ddi

Karger" ysis (234 in RFA and 309 in endoscopic surveillance). The progression of BE-LGD to either HGD or EAC was significantly lower in patients treated with RFA compared to endoscopic surveillance (OR: $0.17,95 \%$ confidence interval [CI]: 0.04$0.65, p=0.01$ ). The progression to HGD alone was significantly lower in patients treated with RFA versus endoscopic surveillance (OR: $0.23,95 \% \mathrm{Cl}: 0.08-0.61, p=0.003)$. The progression to EAC alone was numerically lower in RFA than endoscopic surveillance without statistical significance (OR: 0.44 , 95\% Cl: 0.17-1.16, $p=0.09$ ). Moderate heterogeneity was noted in the analysis. Conclusions: Based on our metaanalysis, there was a significant reduction in the risk of progression to HGD or EAC among patients with BE-LGD treated with RFA compared with those undergoing endoscopic surveillance. Endoscopic eradication therapy with RFA should be the preferred management approach for BE-LGD.

(c) 2021 S. Karger AG, Basel

Jagpal Singh Klair, Yousaf Zafar, share co-1st authorship.
Correspondence to:

Rajesh Krishnamoorthi, rajesh.krishnamoorthi@virginiamason.org 


\section{Introduction}

Barrett's esophagus (BE) is characterized by partial replacement of the normal squamous epithelium of the lower esophagus by a metaplastic columnar epithelium containing goblet cells (intestinal metaplasia). $\mathrm{BE}$ is a premalignant condition with a risk of progression to esophageal adenocarcinoma (EAC) [1-3]. The incidence of EAC has progressively increased over the past 4 decades [4-6]. The prognosis of symptomatic EAC is poor, and it is one of the leading causes of death in USA with a current incidence of roughly 3 cases per 100,000 [7, 8]. To date, the rate of progression of $\mathrm{BE}$ to dysplasia is the most informative metric to predict cancer risk in patients with $\mathrm{BE}$, and therefore, the recommendations are based on these rates. $\mathrm{BE}$ with high-grade dysplasia (HGD) is associated with a 6-19\% annual rate of progression to EAC whereas nondysplastic BE (NDBE) is associated with an annual incidence rate of $0.33 \%$ [9-11]. While the management strategies of NDBE (surveillance) and HGD without any visible lesions (ablation) are very clear, the management of BE-associated low-grade dysplasia (LGD) (endoscopic surveillance vs. ablation) is more challenging [12-14]. The newer guidelines have favored radiofrequency ablation (RFA) as an optimal treatment for BE with LGD [15, 16]. There have been variable rates of progression of LGD to HGD ranging from 0.4 to $13.4 \%$ /year in the literature. The aim of this meta-analysis is to compare the risk of progression of BE with LGD to HGD and EAC after treatment with radiofrequency ablation compared to endoscopic surveillance alone. This will help gain valuable insights on how to best manage patients with BE and LGD to minimize risk of progression to cancer. To the best of our knowledge, this is the first meta-analysis that only included studies with direct comparison of Barrett's ablation therapy with endoscopic surveillance only in patients with BE and LGD.

\section{Materials and Methods}

This systematic review was performed in accordance with Cochrane Handbook for Systematic Reviews of Interventions [17]. It is reported in accordance with Preferred Reporting Items for Systematic Reviews and Meta-Analyses guidelines [18].

\section{Search Strategy}

We conducted a comprehensive search of several databases and conference proceedings, including Medline, EMBASE, Scopus, Cochrane Library, and Web of Science databases (earliest inception to August 2019) to identify studies comparing RFA with endoscopic surveillance in patients with BE with LGD. Literature search was performed by an experienced medical librarian using input from the study authors.

Key words used in the search included a combination BE, LGD, RFA, and endoscopic surveillance. The search was restricted to studies in human subjects published in the English language. Two authors (RK and JSK) independently reviewed the title and abstract of studies identified in the primary search and excluded studies that were not relevant to the research question based on prespecified inclusion and exclusion criteria. The full text of remaining articles was reviewed to determine whether they reported outcomes of interest. Any discrepancy in article selection was resolved by consensus and in discussion with a coauthor. The bibliographic sections of the selected articles, as well as narrative reviews on the topic, were also manually searched for additional relevant studies.

\section{Selection Criteria}

In the meta-analysis, we included studies that met the following inclusion criteria [1]: study population that had BE-LGD and received RFA or endoscopic surveillance [3], reported the rates of progression to HGD and EAC in a certain follow-up period [4], and studies that were comparative in nature [5] sample size of 10 or more patients. We excluded studies (1) that were in any nonEnglish language or that were nonclinical and on nonhuman subjects (2) which did not compare RFA with endoscopic surveillance in patients with BE-LGD (3) letters to the editor, case reports, editorials, and review articles. In case of multiple publications from the same cohort, data from the most recent comprehensive report were included.

\section{Data Abstraction and Quality Assessment}

After identifying relevant studies, data on the study characteristics, patient characteristics, and relevant study outcomes were abstracted onto a standardized form by 2 authors (RK and JSK). The quality of the individual studies was independently assessed by 2 authors (RK and JSK) using the Newcastle-Ottawa scale for cohort studies [19]. The quality scale consisted of 8 questions. Using the scale, the studies were assigned scores under 3 broad perspectives [1]: Selection (4 questions) [3], comparability of study groups (1 question), and [4] ascertainment of the outcome of interest (3 questions). All questions received a score of 1 except for comparability which could get a maximum of 2 . Studies with a total score of 8 , $6-7$, and $\leq 5$ were considered suggestive of high-quality, mediumquality, and low-quality, respectively. Any discrepancies in data abstraction and quality assessment were resolved by joint assessment of the original articles by 2 authors (RK and JSK).

\section{Outcomes}

The primary outcome was to assess the pooled rates of progression to HGD/EAC among BE-LGD patients treated with RFA or endoscopic surveillance. The secondary outcomes were to assess the rates of progression to HGD alone and EAC alone among BELGD patients treated with RFA or endoscopic surveillance.

\section{Statistical Analysis}

Using the random-effects model described by DerSimonian and Laird [20], we calculated the pooled rates of HGD or EAC together, HGD alone and EAC alone with 95\% confidence intervals (CIs). Heterogeneity between study-specific estimates was assessed using inconsistency index (I2 statistic), which estimates the 
Fig. 1. Flowchart summarizing study selec-

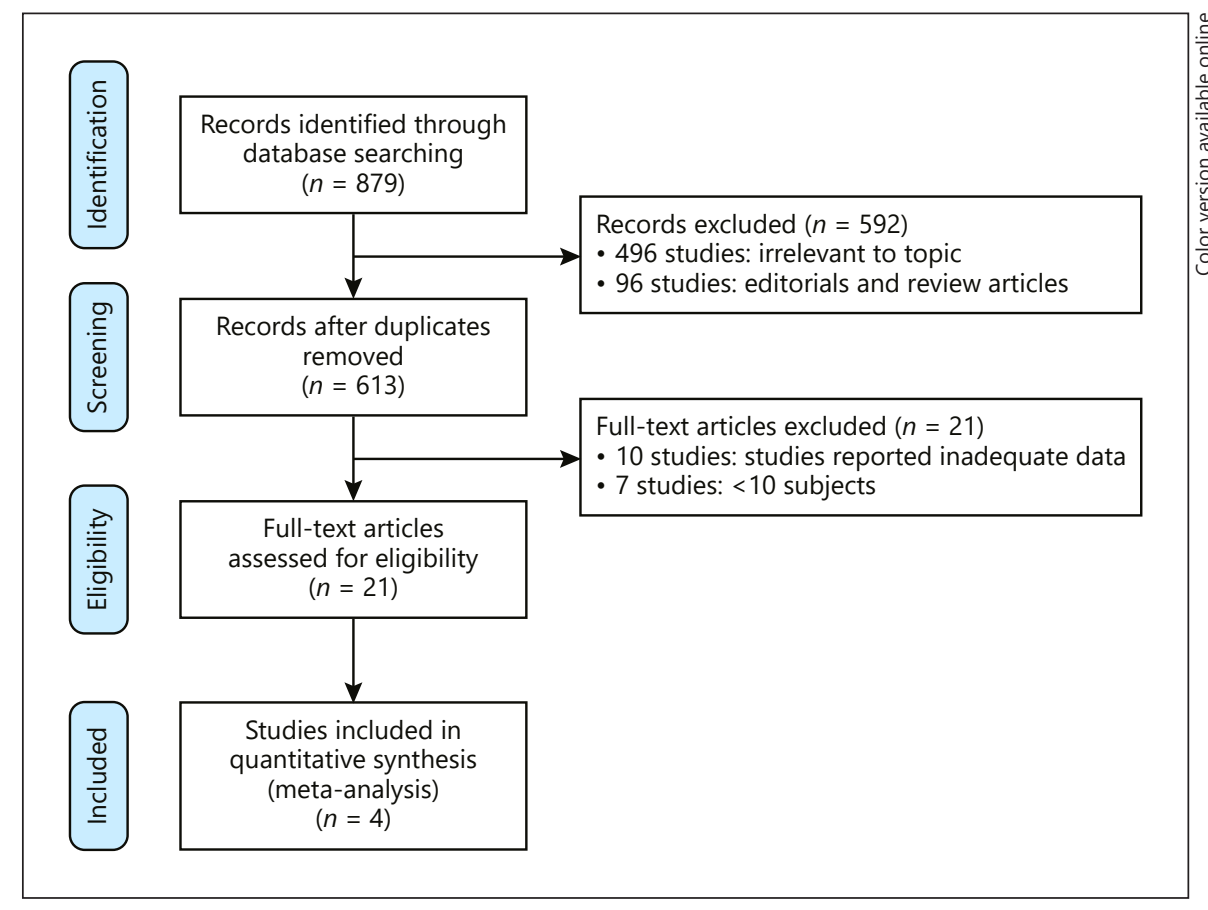
tion process.

Table 1. Study characteristics including BE-LGD comparing HGD versus EAC

\begin{tabular}{llllllll}
\hline Study details & $\begin{array}{l}\text { Year of } \\
\text { publication }\end{array}$ & Country & $\begin{array}{l}\text { Patients } \\
\text { with LGD, } \\
N\end{array}$ & $\begin{array}{l}\text { Mean } \\
\text { age }\end{array}$ & $\begin{array}{l}\text { Males, } \\
\%\end{array}$ & $\begin{array}{l}\text { Median } \\
\text { follow-up, } \\
\text { months }\end{array}$ & $\begin{array}{l}\text { BE length, } \\
\text { cm }\end{array}$ \\
\hline Kahn et al. [21] & 2017 & USA & 173 & 63 & 82 & 86 & 6 \\
Small et al. [22] & 2015 & USA & 170 & 62 & 80 & 29 & 5 \\
Phoa et al. [23] & 2014 & Europe & 136 & 63 & 85 & 36 & 4 \\
Shaheen et al. [8] & 2009 & USA & 64 & 65 & 81 & 12 & 4.6 \\
\hline
\end{tabular}

HGD, high-grade dysplasia; BE-LGD, Barrett's esophagus with low-grade dysplasia; EAC, esophageal adenocarcinoma.

proportion of total variation across studies that is related to heterogeneity rather than by chance. Values of $<30 \%, 30-60 \%, 61-$ $75 \%$, and $>75 \%$ were considered suggestive of low, moderate, substantial, and considerable heterogeneity, respectively [20]. If there were $\geq 10$ studies included in the meta-analysis, we planned to assess for publication bias qualitatively, by visual inspection of funnel plot and quantitatively, by the Egger test [21]. All statistical analyses were performed by using open meta-analyst (CEBM, Brown University, Providence, RI, USA).

\section{Results}

A total of 879 studies were identified by our search criteria. 613 studies were identified after removing duplicate records. After excluding 592 studies based on title and abstract review, 21 full-text articles were reviewed. Ten studies were excluded as they reported inadequate data. 4 studies were excluded as they had $<10$ patients. We identified 4 studies that were included in the final analysis (Table 1). These 4 studies reported outcomes of patients with BE with LGD treated with RFA versus endoscopic surveillance and recorded incidence of $\mathrm{HGD}$ and $\mathrm{EAC}$ over a follow-up period. The schematic diagram of study identification and selection is illustrated in Figure 1.

All 4 included studies used a consistent definition for completion of RFA treatment (CR-D and CR-IM). LGD diagnosis per pathologist varied among the 4 studies. In study by Kahn et al. [21], the diagnosis of BE with LGD frequently, but not always, prompted confirmation by a second gastrointestinal pathologist. In the study by Small 
Fig. 2. Forest plot of rates of disease progression from BE-LGD to HGD or EAC among patients who underwent endoscopic surveillance versus radiofrequency ablation. Kahn et al. [21], Small et al. [22], Phoa et al. [23], and Shaheen et al. [8]. HGD, high-grade dysplasia; BE-LGD, Barrett's esophagus with low-grade dysplasia; EAC, esophageal adenocarcinoma.

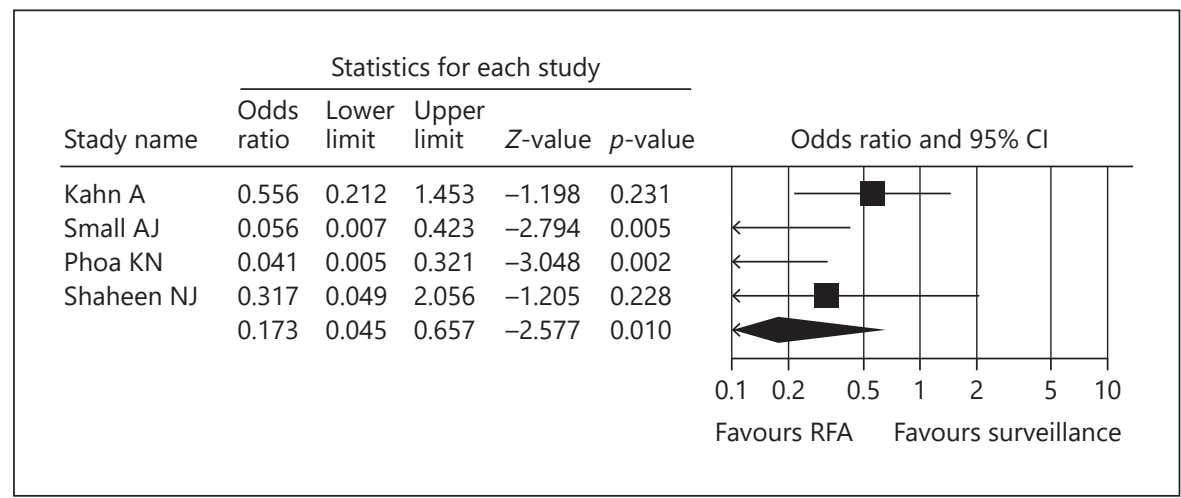

Table 2. Outcomes with RFA and endoscopic surveillance

\begin{tabular}{|c|c|c|c|c|c|c|c|c|}
\hline \multirow[t]{2}{*}{ Study details } & \multicolumn{4}{|c|}{ Radiofrequency ablation } & \multicolumn{4}{|c|}{ Endoscopic surveillance } \\
\hline & $N$ & $\begin{array}{l}\text { progress } \\
\text { HGD }\end{array}$ & $\begin{array}{l}\text { progress } \\
\text { EAC }\end{array}$ & $\begin{array}{l}\text { progress } \\
\text { either }\end{array}$ & $N$ & $\begin{array}{l}\text { progress } \\
\text { HGD }\end{array}$ & $\begin{array}{l}\text { progress } \\
\text { EAC }\end{array}$ & $\begin{array}{l}\text { progress } \\
\text { either }\end{array}$ \\
\hline Kahn et al. [21] & 79 & 3 & 4 & 7 & 94 & 7 & 7 & 14 \\
\hline Small et al. [22] & 45 & 0 & 1 & 1 & 125 & 29 & 7 & 36 \\
\hline Phoa et al. [23] & 68 & 0 & 1 & 1 & 68 & 12 & 6 & 18 \\
\hline Shaheen et al. [8] & 42 & 2 & 0 & 2 & 22 & 3 & 0 & 3 \\
\hline
\end{tabular}

RFA, radiofrequency ablation; HGD, high-grade dysplasia; EAC, esophageal adenocarcinoma.

et al. [22], 1 pathologist with extensive experience in Barrett's diagnosed BE-LGD. In cases of uncertainty, a second and sometimes a third pathologist was needed. In the study by Phoa et al. [23], 2 pathologists were required for the diagnosis of BE with LGD. Sometimes a third pathologist was used in cases of disagreement. Similarly, in the study by Shaheen et al. [8], all cases of BE with LGD underwent a confirmatory masked review by a second pathologist, and in cases of disagreement, a third review with assignment by concordance.

The centers from the included studies performed endoscopic surveillance of the patients with diagnosis of LGD in the similar way. Kahn et al. [21] and Small et al. [22] had a protocol of endoscopies every 6-12 months for $\mathrm{BE}$ with LGD in endoscopic surveillance arm. Phoa et al. [23] and Shaheen et al. [8] had a protocol of endoscopies at 6 months, 12 months, and annually thereafter.

\section{Characteristics of Included Studies}

Study characteristics and quality of the included studies are summarized in Tables 1 and 2. Three studies were multi-center $[9,23,24]$ and 1 study was a single-center studies [22]. All 4 studies were published as manuscripts
$[5,16-18]$. Two of these studies were retrospective in nature $[9,22]$, and 2 were randomized clinical trials $[23,24]$. See online suppl. Table 1; for all online suppl. material, see www.karger.com/doi/10.1159/000514786 summarizes the quality assessment of the included studies. 2 studies were deemed to be high quality $[16,17]$, and 2 studies were deemed to be medium quality $[5,18]$.

\section{Primary Outcome}

Progression of BE-LGD to HGD or EAC

A total of 4 studies reporting 545 patients that were included in this analysis. A total of 11 patients progressed to HGD/EAC in the RFA group whereas 71 patients progressed to HGD/EAC in the endoscopic surveillance only group (Table 2). The progression of BE-LGD progressing to HGD or EAC significantly lower in patients treated with RFA than endoscopic surveillance (OR: 0.17, 95\% CI [0.04-0.65], $p=0.01$ ) (Fig. 2).

\section{Secondary Outcomes}

Progression of BE-LGD to HGD Alone (Fig. 3) and EAC Alone (Fig. 4) 
Fig. 3. Forest plot of rates of disease progression from BE-LGD to HGD alone among patients who underwent endoscopic surveillance versus radiofrequency ablation. Kahn et al. [21], Small et al. [22], Phoa et al. [23], and Shaheen et al. [8]. HGD, high-grade dysplasia; BE-LGD, Barrett's esophagus with low-grade dysplasia.

Fig. 4. Forest plot of rates of disease progression from BE-LGD to EAC alone among patients who underwent endoscopic surveillance versus RFA. Kahn et al. [21], Small et al. [22], and Phoa et al. [23]. RFA, radiofrequency ablation; BE-LGD, Barrett's esophagus with low-grade dysplasia; EAC, esophageal adenocarcinoma.
Statistics for each study

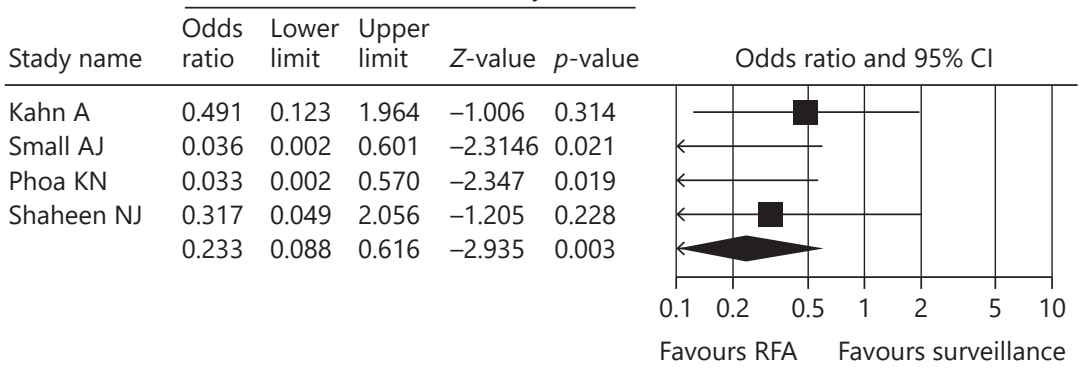

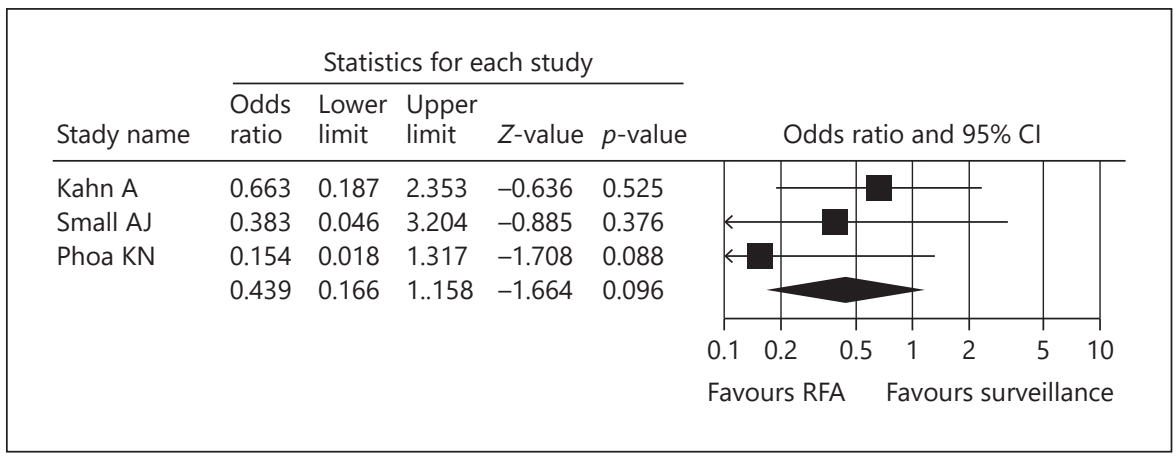

A total of 4 studies reported 55 of the 545 patients progressed to HGD and were used in the analysis. Five patients progressed in the RFA group compared to 50 in the endoscopic surveillance group (Table 2). The progression of HGD alone was significantly lower in the patients treated with RFA versus endoscopic surveillance (OR: 0.23 , 95\% CI: $0.08-0.61, p=0.003$ ) (Fig. 3).

A total of 4 studies reported 20 of the 545 patients progressed to EAC and were used in the analysis. Five patients progressed in the RFA group compared to 20 in the endoscopic surveillance group (Table 2). The progression of EAC alone was much lower in number in the RFA group compared to endoscopic surveillance group without any statistical significance (OR: $0.44,95 \%$ CI: $0.17-$ $1.16, p=0.09$ ) (Fig. 4).

\section{Adverse Events}

Adverse events are significant $(p=0.004)$ in patients undergoing Ablation therapy then those who underwent surveillance therapy. Out of the 4 studies included in this meta-analysis only 3 studies mentioned the incidence of adverse events in the study.

\section{Analysis of Time to Observation}

We analyzed the time of observation for development of HGD and performed a meta-regression on the
4 studies that were included in the current meta-analysis. This was not performed for the incidence of EAC in the follow-up group as the number of studies was not enough as one of the studies did not mention as incidence in both the arms. The meta-regression on the follow-up time period was not significant for the different follow-up times of the 4 included studies $p=0.49$. This does indicate that the results would be valid despite variability in the follow-up time period of the studies (Fig. 5).

\section{Heterogeneity}

The heterogeneity $\left(\mathrm{I}^{2}\right)$ was moderate in the with regard to the progression from LGD to HGD or EAC ( $\mathrm{Q} d f=3$, $I^{2}=63.1$ ). This could indicate that $63.1 \%$ of the heterogeneity seen was a result of the kind of patients that were selected for RFA or endoscopic surveillance in patients with BE-LGD.

\section{Publication Bias}

Based on visual inspection of the funnel plot as well as quantitative measurement using Egger's test, there was evidence of publication bias $(p<0.01)$. Given considerable heterogeneity observed in the analysis, the assessment of the publication bias should be interpreted with caution. Funnel plots \& Duval and Tweedie's trim-and- 


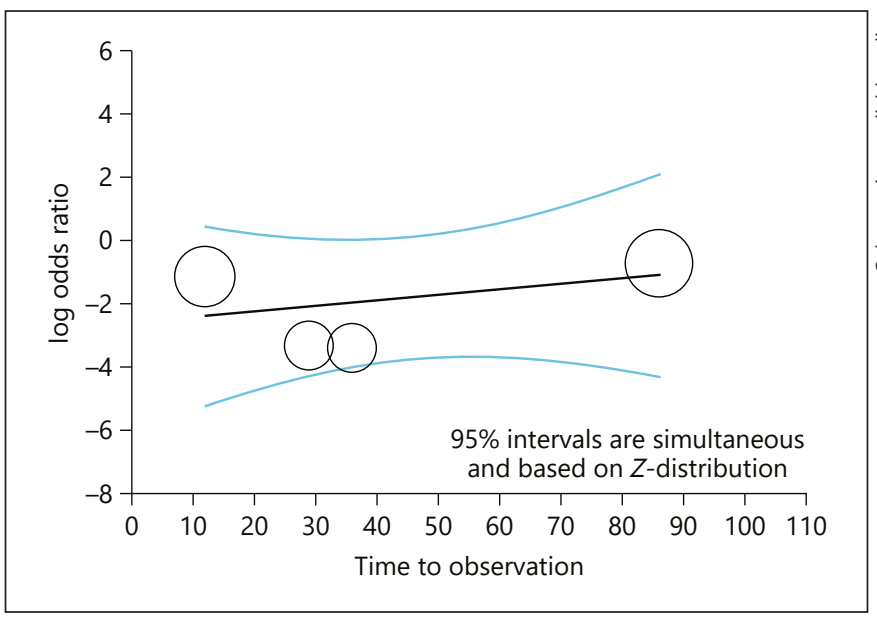

Fig. 5. Analysis of the time of observation for development of HGD. HGD, high-grade dysplasia

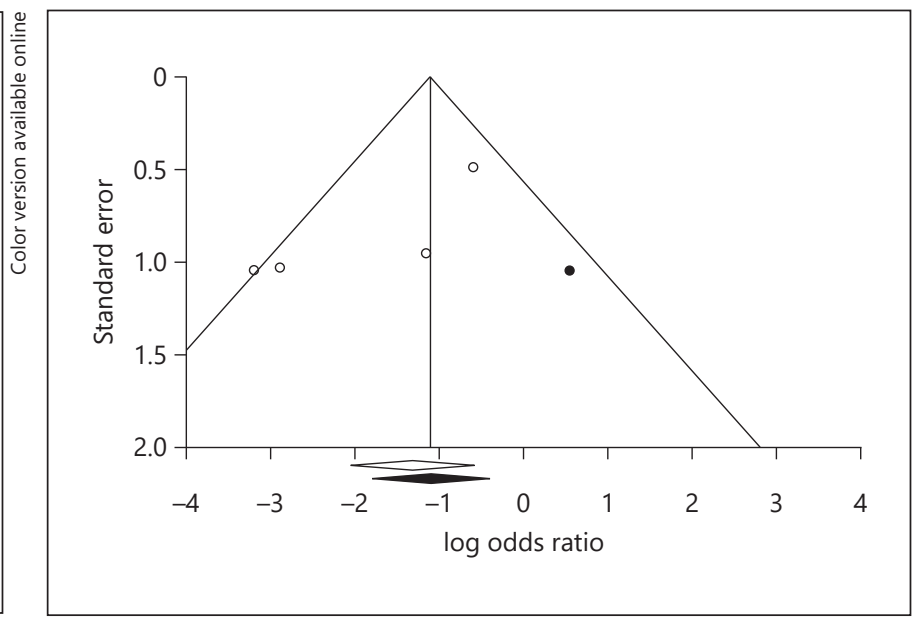

Fig. 6. Funnel plot for publication bias.

\begin{tabular}{|c|c|c|c|c|c|c|c|c|}
\hline \multirow[b]{2}{*}{ Stady name } & \multirow[b]{2}{*}{$\begin{array}{l}\text { Studies } \\
\text { trimmed }\end{array}$} & \multicolumn{3}{|c|}{ Fixed effects } & \multicolumn{3}{|c|}{ Random effects } & \multirow[b]{2}{*}{ Q-value } \\
\hline & & $\begin{array}{l}\text { Point } \\
\text { estimate }\end{array}$ & $\begin{array}{l}\text { Lower } \\
\text { limit }\end{array}$ & $\begin{array}{l}\text { Upper } \\
\text { limit }\end{array}$ & $\begin{array}{l}\text { Point } \\
\text { estimate }\end{array}$ & $\begin{array}{l}\text { Lower } \\
\text { limit }\end{array}$ & $\begin{array}{l}\text { Upper } \\
\text { limit }\end{array}$ & \\
\hline Observed values & & 0.26910 & 0.12904 & 0.56119 & 0.17272 & 0.04542 & 0.65684 & 7.73130 \\
\hline Adjusted values & 1 & 0.33305 & 0.16676 & 0.66515 & 0.25684 & 0.07373 & 0.89471 & 10.56126 \\
\hline
\end{tabular}

Fig. 7. Duval and Tweedie's trim and fill analysis.

fill analysis were performed. Using trim and fill, the imputed point estimate for EAC/HGD was 0.33 (0.17-0.66) (Fig. 6, 7).

\section{Discussion}

$\mathrm{BE}$ is a common risk factor for progression to $\mathrm{HGD}$ and EAC. Although there is strong consensus on the management of BE-HGD, the guidelines on the management of BE-LGD are not very distinct. Our study showed that the progression of BE-LGD to either HGD or EAC was significantly lower in patients treated with RFA than endoscopic surveillance (OR: 0.17, 95\% CI: 0.04-0.65, $p=0.01)$. The progression to HGD alone was significantly lower in patients treated with RFA versus endoscopic surveillance (OR: $0.23,95 \%$ CI: $0.08-0.61, p=0.003$ ). The progression to EAC alone was numerically lower in RFA than endoscopic surveillance without statistical signifi- cance (OR: 0.44, 95\% CI: 0.17-1.16, $p=0.09$ ). This is important as there is sequential progression of BE with LGD to EAC via HGD. A significant proportion of patients diagnosed with HGD are treated and do not develop EAC. This can explain the statistically insignificant lower risk of progression to EAC in patients who underwent RFA. The results showed a reduction in the risk of progression to HGD/EAC with treatment of patients with BE-LGD with RFA compared with endoscopic surveillance. The results were consistent when we assessed progression to EAC or HGD separately although it was not statistically significant for patients when comparing EAC alone ( $p=$ 0.09 ). Reasons for possible preference of endoscopic surveillance over RFA could be because it is considered relatively less invasive than that latter and that BE-LGD may regress over time in majority of the cases without any intervention. But the RFA does eradicate the chance of progression of LGD to EAC (even if the incidence is minimal) which has a poor prognosis. The goal of the meta- 
analysis was to determine if a certain modality for screening and preferred over the other for management of BE-LGD. Our results do highlight that RFA is superior to endoscopic surveillance in preventing the disease progression to HGD/EA. Therefore, RFA should be considered when making recommendations to patients who carry the diagnosis of BE-LGD.

The follow-up time period between the 4 studies (1286 months) was variable. This could possibly affect the number of patients that would progress to HGD/EAC, but the progression of this disease does fall within a span of a few years [25]. While comparing the studies included in the current meta-analysis, the number of patients that progressed to HGD was $3.7 \%$ in 86 -month follow-up group [22] and was $4.7 \%$ in the 12-month RFA follow-up group [9]. A downward trend over a longer follow-up period was also observed in the endoscopic surveillance group that progressed to HGD in $13.6 \%$ of the patients that were being followed in 12-month follow-up whereas it was $7.4 \%$ in the group being followed for 86 months follow-up period. Our current analyses showed similar results when the analysis was restricted to an end point of progression to HGD only but was not statistically significant in the EAC only group. This could be because the total number of studies was limited with one of the studies limited to only 12 months of follow-up. Thus, regardless of how the data were analyzed, results were consistent in the beneficial effect of RFA when compared with endoscopic surveillance.

It is also important to note that the diagnosis of BELGD requires expert pathology review [26]. There is significant intra- and interobserver variability among pathologists, especially in the differentiation between NDBE, indefinite for dysplasia and LGD. Studies have shown that when LGD is diagnosed by a consensus agreement of 2 or more expert GI pathologists, its progression toward malignancy seems to be at least 3 times more likely than when a single pathologist makes a diagnosis of LGD, however, the incidence of progression could be up to 20 times more [27]. It is, therefore, recommended that biopsies of all BE patients with LGD should be reviewed by 2 expert GI pathologists to prevent any missed opportunity for diagnosis. Given the higher risk of disease progression in these confirmed cases, our evidence suggests that such patients who are medically fit to undergo endoscopic therapy should be offered RFA rather than endoscopic surveillance.

The current meta-analysis has several limitations. Two of the 4 included studies were retrospective in nature. The heterogeneity was moderate to considerable in the pooled analyses of clinical and technical success. The follow-up between the 4 studies was variable could explain why there was no statistical difference observed in the EAC group when comparing RFA with endoscopic surveillance in BE-LGD patients. A previous meta-analysis by Pandey et al. on effectiveness of RFA on BE-LGD included 8 studies [28]. This included 5 noncomparative studies (RFA alone) and 3 comparative studies (RFA vs. surveillance). While the primary outcome of the prior study was pooled rate of CE-IM/CE-D with RFA, it also reported a secondary outcome of progression risk (HGD or EAC) with RFA versus surveillance (3 studies). Unlike the prior study, we only included comparative studies with 2 arms (RFA and surveillance) and compared the risk of HGD/EAC, HGD alone, and EAC alone (RFA vs. surveillance).

The major strength of the current meta-analysis is that we only included studies comparing outcomes of BE-LGD patients receiving either RFA or endoscopic surveillance. To our knowledge, this is the only metaanalysis that has only included studies that compared RFA with endoscopic surveillance for BE-LGD patients. The other strengths include comprehensive and systematic literature search of multiple databases; strict well-defined inclusion and exclusion criteria; careful avoidance of redundant studies; and a detailed quality assessment.

In conclusion, RFA appears to be an effective modality with lower rates of progression from BE-LGD to HGD/ EAC. Given these results, RFA could be considered as the preferred management option in patients with $\mathrm{BE}$ with LGD.

\section{Statement of Ethics}

The current study has complied with the guidelines for human studies and the research was conducted ethically in accordance with the World Medical Association Declaration of Helsinki.

\section{Conflict of Interest Statement} close.

The authors have no conflicts of interest or financial ties to dis-

\section{Funding Sources}

No funding was obtained for this study. 


\section{Author Contributions}

Jagpal Singh Klair - manuscript inception, data acquisition and statistical analysis, and drafting of the manuscript. Yousaf $\mathrm{Za}$ far - data acquisition and statistical analysis, drafting of the manuscript. Navroop Nagra - drafting of the manuscript. Arvind R. Mu- rali - data acquisition and statistical analysis, critical revision, and final approval. Mahendran Jayaraj - manuscript inception, drafting of the manuscript. Dhruv Singh - data acquisition and statistical analysis. Tarun Rustagi - critical revision and final approval. Rajesh Krishnamoorthi - manuscript inception, data acquisition and statistical analysis, critical revision, and final approval.

\section{References}

1 Chow WH, Blot WJ, Vaughan TL, Risch HA, Gammon MD, Stanford JL, et al. Body mass index and risk of adenocarcinomas of the esophagus and gastric cardia. J Natl Cancer Inst. 1998;90(2):150-5.

2 Brown LM, Silverman DT, Pottern LM, Schoenberg JB, Greenberg RS, Swanson GM, et al. Adenocarcinoma of the esophagus and esophagogastric junction in white men in the United States: alcohol, tobacco, and socioeconomic factors. Cancer Causes Control. 1994; 5(4):333-40.

3 Then EO, Lopez M, Saleem S, Gayam V, Sunkara T, Culliford A, et al. Esophageal cancer: an updated surveillance epidemiology and end results database analysis. World J Oncol. 2020;11(2):55-64.

4 Siegel RL, Miller KD, Jemal A. Cancer statistics, 2016. CA Cancer J Clin. 2019;66(1):7-30.

5 Pera M, Manterola C, Vidal O, Grande L. Epidemiology of esophageal adenocarcinoma. J Surg Oncol. 2005;92(3):151-9.

6 Hur C, Miller M, Kong CY, Dowling EC, Nattinger KJ, Dunn M, et al. Trends in esophageal adenocarcinoma incidence and mortality. Cancer. 2013;119(6):1149-58.

7 El-Serag HB, Sweet S, Winchester CC, Dent J. Update on the epidemiology of gastro-oesophageal reflux disease: a systematic review. Gut. 2014;63(6):871-80.

8 Shaheen NJ, Sharma P, Overholt BF, Wolfsen HC, Sampliner RE, Wang KK, et al. Radiofrequency ablation in Barrett's esophagus with dysplasia. N Engl J Med. 2009;360(22):227788.

9 Rastogi A, Puli S, El-Serag HB, Bansal A, Wani S, Sharma P. Incidence of esophageal adenocarcinoma in patients with Barrett's esophagus and high-grade dysplasia: a metaanalysis. Gastrointest Endosc. 2008;67(3): 394-8.

10 Desai TK, Krishnan K, Samala N, Singh J, Cluley J, Perla S, et al. The incidence of oesophageal adenocarcinoma in non-dysplastic Barrett's oesophagus: a meta-analysis. Gut. 2012;61(7):970-6.
11 Shaheen NJ, Falk GW, Iyer PG, Gerson LB, American College of G. ACG clinical guideline: diagnosis and management of Barrett's esophagus. Am J Gastroenterol. 2016;111(1): $30-51$.

12 American Gastroenterological; Spechler SJ, Sharma P, Souza RF, Inadomi JM, Shaheen NJ. American gastroenterological association medical position statement on the management of Barrett's esophagus. Gastroenterology. 2011;140(3):1084-91

13 Fitzgerald RC, di Pietro M, Ragunath K, Ang Y, Kang JY, Watson P, et al. British society of gastroenterology guidelines on the diagnosis and management of Barrett's oesophagus. Gut. 2014;63(1):7-42.

14 Sharma P, Shaheen NJ, Katzka D, Bergman J. AGA clinical practice update on endoscopic treatment of barrett's esophagus with dysplasia and/or early cancer: expert review. Gastroenterology. 2020;158(3):760-9.

15 di Pietro M, Fitzgerald RC, BSGBsgw group. Revised British society of gastroenterology recommendation on the diagnosis and management of Barrett's oesophagus with lowgrade dysplasia. Gut. 2018;67(2):392-3.

16 Higgins J GS. cochrane handbook of systematic reviews of interventions version 5.1.0. 2011.

17 Moher D, Liberati A, Tetzlaff J, Altman DG, Group P. Preferred reporting items for systematic reviews and meta-analyses: the PRISMA statement. J Clin Epidemiol. 2009;62(10): 1006-12.

18 Easterbrook PJ, Berlin JA, Gopalan R, Matthews DR. Publication bias in clinical research. Lancet. 1991;337(8746):867-72.

19 DerSimonian R, Laird N. Meta-analysis in clinical trials. Control Clin Trials. 1986;7(3): $177-88$.

20 Guyatt GH, Oxman AD, Kunz R, Woodcock J, Brozek J, Helfand M, et al. GRADE guidelines: 7. Rating the quality of evidence: inconsistency. J Clin Epidemiol. 2011;64(12):1294302.
21 Kahn A, Al-Qaisi M, Kommineni VT, Callaway JK, Boroff ES, Burdick GE, et al. Longitudinal outcomes of radiofrequency ablation versus surveillance endoscopy for Barrett's esophagus with low-grade dysplasia. Dis Esophagus. 2018;31(4):120.

22 Small AJ, Araujo JL, Leggett CL, Mendelson AH, Agarwalla A, Abrams JA, et al. Radiofrequency ablation is associated with decreased neoplastic progression in patients with Barrett's esophagus and confirmed low-grade dysplasia. Gastroenterology. 2015;149(3): $567-76$

23 Phoa KN, van Vilsteren FG, Weusten BL, Bisschops R, Schoon EJ, Ragunath K, et al. Radiofrequency ablation vs endoscopic surveillance for patients with Barrett esophagus and low-grade dysplasia: a randomized clinical trial. JAMA. 2014;311(12):1209-17.

24 Rabinovitch PS, Longton G, Blount PL, Levine DS, Reid BJ. Predictors of progression in Barrett's esophagus III: baseline flow cytometric variables. Am J Gastroenterol. 2001; 96(11):3071-83.

25 Krishnamoorthi R, Hargraves I, Gopalakrishnan N, Blevins CH, Priyan H, Johnson ML, et al. Development and pilot testing of decision aid for shared decision making in Barrett's esophagus with low-grade dysplasia. J Clin Gastroenterol. 2020.

26 Moole H, Patel J, Ahmed Z, Duvvuri A, Vennelaganti S, Moole V, et al. Progression from low-grade dysplasia to malignancy in patients with Barrett's esophagus diagnosed by two or more pathologists. World J Gastroenterol. 2016;22(39):8831-43.

27 Skacel M, Petras RE, Gramlich TL, Sigel JE, Richter JE, Goldblum JR. The diagnosis of low-grade dysplasia in Barrett's esophagus and its implications for disease progression. Am J Gastroenterol. 2000;95(12):3383-7.

28 Pandey G, Mulla M, Lewis WG, Foliaki A, Chan DSY. Systematic review and meta-analysis of the effectiveness of radiofrequency ablation in low grade dysplastic Barrett's esophagus. Endoscopy. 2018;50(10):953-960. 